\section{METALLIC CORROSION}

The Corrosion and Oxidation of Metals Scientific Principles and Practical Applications. By Dr. Ulick R. Evans. Pp. xi+1094. (London: Edward Arnold (Publishers), Ltd., 1960.) 140s. net.

T $T$ is largely owing to the work and teaching of 1 Dr. Ulick Evans that the subject of metallic corrosion and protection can properly be said to have achieved scientific status. Although, as he is careful to point out in another book, extensive studies of the subject were being made at a number of laboratories at the turn of this century, it was not until his group at Cambridge began its work in 1923 that the electrochemical basis of wet corrosion became firmly established. Since that time, no one concerned with either the causes or the results of corrosion could afford to ignore the prodigious amount of first-class fundamental work accomplished by Dr. Evans and his school. Nor could they safely ignore the successive editions of his book "Metallic Corrosion, Passivity and Protection" which have so lucidly marshalled the facts and theories relating to this important subject and always with copious references to the current scientific literature. Many students, too, will be familiar with his shorter version "An Introduction to Metallic Corrosion", which has formed the basis (and sometimes the totality) of their college corrosion lectures.

Dr. Evans' new book is completely up to date. It contains references to some 6,500 published papers, a high proportion of them appearing since 1950 and some of these as recently as the early months of 1959. For some readers it will, therefore, serve chiefly as an up-to-date book of sources, which are now incidentally grouped at the ends of relevant paragraphs and chapters, together with much useful commentary. The inevitable selection which has gone to produce even this enormous number of references is in many ways beneficial, for we are left with only that work which the author deems to have been of importance in forming his views or which presents stimulating or conflicting data and theories. For many, however, the chief advantage of the book lies in the arrangement of the material. Very little of the pattern-or, indeed, the matter-of earlier books remains. Instead, the twenty-two chapters have been so written as to be self-contained, and each is prefaced by an excellent synopsis which, besides summarizing its contents, relates it to other parts of the book.

The first chapter is in the nature of an apologia and demonstrates the importance of an understand ing of the subject for engineers, architects, economists and public health authorities as well as for many pure scientists. In the next seventeen chapters (756 pp.), the author gives us his personal views on the qualitative aspects of corrosion, oxidation and protection. Included in this section is a new chapter on what he describes as 'crystallographic' corrosion, that is the way in which surface features on an atomic scale influence the mode and distribution of metal dissolution. Then he gives us four chapters (I84 pp.) in which the quantitative aspocts are discussed in more detail, together with the laboratory measurements upon which these are based. Finally, there are two appendixes, which, in the incredibly short span of 91 pages, provide a concentrated course in chemistry, electrochemistry and electrokinetics. Although. showing signs of hasty preparation, being marred by several misprints, these appendixes should prove of enormous help in providing the necessary scientific background for the 'non-technical' reader; and at least one electrochemist found them to constitute rather more than a refresher course. Perhaps, however, we could have had a little more about exchange currents and the differences between the hydrogen and oxygen reactions in this respect, in view of their important bearing on over-potential in corrosion and electroplating systems.

As well as re-arranging his material, the author has slightly expanded it (what was 800 pages in the 1948 edition of "Metallic Corrosion, Passivity and Protection" is now 940 pages), in particular as regards the conjoint action of stress and corrosion, hydrogen cracking and the corrosion of buried metals. Four chapters are devoted to oxidation, six to electrochemical corrosion, three to a consideration of practical environments (for example, boilers), three to conjoint effects (stress-corrosion, corrosion fatigue and fretting corrosion), three to corrosion protection (coatings and inhibitors) and there are two chapters on testing methods and the statistical treatment of data.

One could not wish for a more comprehensive or well-written book, and, despite the threefold increase in price since "Metallic Corrosion, Passivity and Protection" in 1948, there can be no doubt that it constitutes a 'must' for anyone hoping to keep abreast of corrosion science and practice.

\section{J. M. WEST}

\section{PROGRESS IN NUCLEAR SCIENCE}

\section{Annual Review of Nuclear Science}

Vol. 9. Editod by Emilio Segxè and Leonard I. Schiff, in association with Gerhart Friedlander and Walter E. Meyerhof. Pp. vii +625 . (Palo Alto, Calif. : Annual Reviews, Inc., 1959. Published in co-operation with the National Research Council of the National Academy of Sciences.) 7 dollars.

HE ninth volume of this series maintains the high standard set in previous yecrs. Wilkinson reviews the recent, and on the whole satisfactory, developments in the theoretical interpretation of nuclear photodisintegration experiments. The highenergy field is again prominent. Chew contributes a clear and concise discussion of the recent field theoretical approach to pion-nucleon interactions through dispersion relations and 'polology'. This is a difficult subject but of groat importance for the understanding of high-energy interactions. Highenergy nuclear reactions are discussed by Miller and Hudis. This embraces spallation, fragmentation and fission at $100 \mathrm{MeV}$. or more and includes a detailed compilation. Okun' (Moscow) discusses the weak interactions, that is the decay properties of the new strange particles. This is the portion of high-energy physics which is changing most rapidly. Konopinski contributes a most useful review of $\beta$-decay theory which is timely now that the violation of parity 'rovolution' is complete. It complements Okun's article admirably.

Four reviews of very genoral interest are nucloar fission by Halpern, nuclear electronics by Kendall, plasma and fusion research by Post and fast reactors by Koch and Paxton. In all these subjects many interesting devolopments can be reported. An article 